\title{
Disease and Treatment Experiences of COVID-19 Patients: A Qualitative Study
}

\author{
Ceyda Uzun Sahin' (D, Merve Aydin ${ }^{2}$ (D, Abdullah Usta ${ }^{3}$ (D), Mustafa Sakin ${ }^{4}$ (D) \\ 'Department of Medical Services and Techniques, First and Emergency Program, Recep Tayyip Erdoğan University Vocational School of \\ Health Services, Rize, Turkey \\ ${ }^{2}$ Department of Mental Health and Psychiatric Nursing, Karadeniz Technical University Faculty of Health Sciences, Trabzon, Turkey \\ ${ }^{3}$ Rize Public Hospital, Surgical Intensive Care Unit, Rize, Turkey \\ ${ }^{4}$ Department of Anesthesia and Reanimation, Rize Provincial Health Directorate, Rize, Turkey
}

ORCID iDs of the authors: C.U.S. 0000-0002-1392-7409; M.A. 0000-000I-7466-2I36; A.U. 0000-000I-9463-4458; M.S. 0000-0002-20788689.

Cite this article as: Uzun Sahin C, Aydin M, Usta A, Sakin M. Disease and Treatment Experiences of COVID-19 Patients: A Qualitative Study. Cyprus J Med Sci 2021; 6(2): 129-135.

\section{BACKGROUND/AIMS}

The study aimed to explore the perceptions of hospitalized COVID-19 patients' experiences regarding the disease and treatment process.

\section{MATERIAL and METHODS}

The study was carried out as qualitative research at a hospital in Turkey between June 17, 2020 and July 7, 2020. The sample consisted of eight COVID-19 patients hospitalized in service after intensive care treatment. The data were collected through an in-depth individual interview form. Each interview was transcribed verbatim, and a thematic analysis was performed. The Standards for Reporting Qualitative Research checklist was followed.

\section{RESULTS}

Three main themes were identified for patients' perceptions of the disease experiences and treatment process. The patients experienced negative emotions after being diagnosed with COVID-19, and they spent the isolation and treatment process communicating with their beloved ones over the phone, watching television, and praying. Having an infectious disease caused them to have anxiety and sadness, and they reported satisfaction with the physicians and nurses during the treatment process.

\section{CONCLUSION}

Psychological and sociocultural factors, religious values, and health policies can be effective in patients' perception of disease and treatment. It is recommended for healthcare professionals to be aware of the psychosocial problems of the hospitalized COVID-19 patients during the disease and treatment process, monitor them for post-traumatic stress disorder, and provide the necessary support.

Keywords: COVID-19, patient, disease perception, qualitative research

\section{INTRODUCTION}

Coronaviruses have been reported to cause mild and moderate respiratory infections in the last 50 years.' However, recently detected coronaviruses severe acute respiratory syndrome (SARS) CoV (2002) and Middle East respiratory syndrome (MERS)-CoV (20I2) have changed all current information as they cause severe acute respiratory infections and nosocomial pandemics. Novel coronavirus, now known as SARS-CoV-2 (2019), appeared in Wuhan, China, at the end of 2019, and the World Health Organization (WHO) declared the outbreak as an alarming international public health issue on January $31,2020 .^{2}$

Just after the first case was confirmed in Turkey on March II, 2020, the WHO declared COVID-19 as a pandemic. According to the data by WHO on February 24, 202I, the number of people infected with SARS-CoV-2 exceeded III million, and more than 2.5 million people have lost their lives so far. Additionally, COVID-19 cases have been reported on all continents except Antarctica, and the number of cases and deaths continues to increase in many countries. ${ }^{3}$ An increase in 
the number of cases has been observed since the detection of the virus in Turkey. The total numbers of COVID-19 cases and deaths were 2,665,194 and 28,285, respectively, until February $24,2021{ }^{4}$

The ongoing COVID-19 pandemic is a serious global public health issue. ${ }^{5}$ The literature cites that pandemics create significant psychosocial problems for healthcare workers, children, and the older adults. ${ }^{6-8}$ The most affected group in this process is undoubtedly the patients treated with the diagnosis of COVID-19. Kong et al. ${ }^{9}$ reported that 34.7 and $28.4 \%$ of COVID19 patients showed anxiety and depression symptoms, respectively. Yang et al. ${ }^{10}$ revealed varying rates of depression, anxiety, and sleep problems in COVID-19 patients treated in the isolation service. Qi et al." determined post-traumatic stress disorder in $12.2 \%$, anxiety/depression in $26.8 \%$, and fatigue symptoms in $53.6 \%$ of 105 COVID-19 patients included in their study.

Asymptomatic or paucisymptomatic forms, respiratory failure, requiring mechanical ventilation and support in the intensive care unit, and even systemic multiorgan failure syndromes can be observed among the signs and symptoms of COVID-19.12,13 However, the impacts of the COVID-19 outbreak on survivors are not just physical signs and symptoms. The psychological effects of the disease are immediately apparent and even permanent for a long time. Survivors of previous infectious disease outbreaks such as SARS and the MERS coronaviruses have been reported to have fear, paranoia, panic, anxiety and mental health disorders, and behavioral and attitudinal psychological responses. ${ }^{14,15}$ Determining the patients' perception of the disease and the associated factors is crucial to reduce anxiety, adaptation, and help them to express their feelings. Knowing patients' perception of the disease and the associated factors is also essential for the governments and health authorities to effectively intervene and be prepared for the psychosocial aspects of the disease.

This study was conducted to guide psychosocial interventions during and after treatment by defining the perceptions of the disease experiences and treatment processes of the hospitalized COVID-19 patients. It is believed that the research will contribute to the literature by revealing the feelings and situations that are prominent in the patients' perception of the dis-

\section{Main Points}

- Three main themes were identified for patients' perceptions of the disease experiences and treatment process.

- Many participants experienced negative feelings during the treatment process, but they were only able to develop short-term coping mechanisms to cope with these emotions.

- Having a fatal and infectious disease had negative psychological impacts on the participants.

- COVID-19 patients mentioned their satisfaction with the physicians and nurses during the treatment process.

- Participants worry about being excluded and stigmatized by their social environment after discharge. ease, the psychosocial needs of the patients, and their perceptions about the treatment and discharge process.

\section{MATERIAL and METHODS}

\section{Design}

This study is qualitative research in a phenomenological pattern. The Standards for Reporting Qualitative Research guideline and Colaizzi's phenomenological method were followed in the study. ${ }^{16,17}$ Colaizzi's phenomenological method focuses on the experience and feelings of subjects and reveals shared patterns rather than individual characteristics. It is a scientific approach that ensures that the experiences collected from the participants adhere to scientific standards.

\section{Research Group Feature and Reflexivity}

The research group in the study includes an instructor (PhD), a research assistant $(\mathrm{PhD})$, a physician (PhD), and an intensive care nurse (MSc). One of the researchers (M.A.) works in the Department of Mental Health and Psychiatric Nursing at the Faculty of Health Sciences. The interviewer (A.U.) possessed a Master of Science in Psychiatric Nursing and has worked as a chief nurse in the COVID-19 intensive care unit. Two of the researchers were nurses in the past (C.U.S. and M.A.). Two of the researchers are women, and two are men, and all of them have been conducting research on qualitative research. Two researchers (C.U.S. and M.A.) took courses from an expert in Qualitative Research Methods at the Department of Psychology at Oxford University and continue to take advanced courses on the related field.

\section{Setting and Time}

The data were collected at a hospital located in Rize, a town in the Black Sea Region, through semistructured in-depth interviews performed between June 17, 2020, and July 7, 2020. The sample was calculated using the purposeful sampling method. ${ }^{18}$ The basic understanding of the criteria sampling method is to work with the studying group meeting a set of predefined criteria. Accordingly, patients hospitalized in COVID-19 service were planned to be included in the study.

The inclusion criteria for the study are as follows:

- being diagnosed with COVID-19 and receiving treatment;

- being a COVID-19 patient hospitalized in service after intensive care treatment;

- being 18 years old and above;

- not having any mental disorder diagnosis;

- being able to communicate (not being connected to the breathing apparatus, speaking Turkish); and

- participating in the study voluntarily.

In total, eight patients fulfilling the preset criteria were included in the sample $(n=8)$.

\section{Data Collection}

In qualitative research, the data are collected until the concepts for the possible answer to the research question start to repeat. $^{19}$ At that point, the researcher decides the sample number sufficiency. Based on this principle, the sample number 
of the research is maintained until the researcher reaches the saturation point. ${ }^{20}$

The data were collected using a Semi-Structured Interview Form and the questionnaire form developed by the researchers. The questionnaire form consists of two parts and 13 questions. In the first part, nine questions are investigating sociodemographic characteristics (age, gender, marital status, place of residence, education level, employment status, perception of income level, having children, and having a chronic disease). The second part includes four questions about the COVID-19 pandemic (having a family member diagnosed with COVID-19, symptoms of COVID-19, being connected to a ventilator, and being a volunteer for plasmapheresis treatment).

During the preparation of interview questions, two experienced external academics in qualitative research were consulted. The researchers then reviewed the literature and prepared the Semi-Structured Interview Form, ${ }^{21,22}$ including three openended questions as follows:

- What are your feelings/experiences about being diagnosed with COVID-19?

- How did you feel during treatment in isolation, and how did you manage this process?

- What do you think about the treatment (process and personnel)?

We informed the population about the purpose and significance of the study in advance and planned the appropriate meeting time with the participants who voluntarily accepted to take part in the study. We also explained that the interviews would be recorded using a tape recorder, their privacy and confidentiality would be protected, and obtained their consent. The questions that were not clear to the patient were explained without any guidance. The data were collected using face to face interview method in a patient room in the COVID19 clinic. One researcher (A.U.) conducted in-person semistructured interviews, and each took between 40 and 60 minutes. The interviewer, wearing protective equipment (N95 mask, gloves, goggles/face protector, apron), made an individual interview face to face, providing a minimum distance of $1 \mathrm{~m}$.

\section{Analysis of the Data}

Within 24 hours after each interview, the recordings were transcribed by a researcher (M.S.) and analyzed following the steps of Colaizzi's phenomenological analysis method. Two researchers (C.U. and M.A.) independently examined the interview materials, identified meaningful statements, created codes, and agreed on common codes. Then, the themes were developed after the data were read several times and coded. ${ }^{23}$ The themes and codes were checked by an external expert. The steps of Collaizi's phenomenological data analysis are as follows:

I. The researcher read the accounts of the participants several times to familiarize and understand the meanings attributed to the phenomenon and the emotions.

2. Significant statements that are of direct relevance to the phenomenon are selected.

3. The significant statements are examined, and meanings are formulated.
4. The formulated meanings are clustered into subthemes, themes, and categories.

5. The emerging themes are combined with full and comprehensive life experiences.

6. The fundamental conceptual structure of the phenomenon is defined.

7. Some participants are reinterviewed, and the results obtained are verified by comparing them with their own experiences. ${ }^{17}$

\section{Validity and Reliability}

There is no specific method to ensure the validity and reliability of qualitative inquiry. The validity and reliability of qualitative research are ensured through credibility, dependability, confirmability, and transferability. ${ }^{24}$ For credibility, the relationships between the themes obtained as a result of this study and the subthemes were checked for integrity. The audio recordings of the interviews with the participants were transcribed verbatim. A purposeful sampling method was used for transferability, and homogeneity was ensured. To check the reliability of the findings, the researchers analyzed the data independently. In the coding process, each researcher coded the transcripts independently, and then they agreed on common codes. For confirmability, semistructured interviews form and thematization were checked by an external expert.

\section{Ethical Considerations}

Ethical approval for the study was received from the local Ethics Committee of Recep Tayyip Erdoğan University (No: 40465587050.01.04-127), and permission was granted by the Council for Scientific Research Studies of the Directorate General of Health Services affiliated to the Ministry of Health, Republic of Turkey (No: 2020-05-02TI4-15-59). At the beginning of the interviews, the participants were first informed about the study and the provisions of the 1995 Declaration of Helsinki (as revised in Brazil, 2013), and their written and verbal consents were obtained.

\section{RESULTS}

The mean age of eight participants was $38.86 \pm 7.66$ years (min: 28; max: 47), four (50\%) were female, five (62.5\%) were married, six (75\%) were living in the city, six (75\%) were high school graduates, and five (62.5\%) had a family member diagnosed with COVID-19 (Table I). COVID-19 patients' experiences about the disease and treatment were collected under three main themes depending on the data analysis: "psychosocial effects," "coping styles," and "provision of health services." The themes, categories, and codes identified through interviews with patients are presented (Table 2).

\section{Theme I: Emotional Reflections about the Disease}

Many participants $(n=5)$ stated that they had negative emotional responses such as fear, panic, anxiety, and anger, but few participants $(n=3)$ gave positive emotional responses such as hope, belief, and adaptation due to COVID-19 diagnosis. They reported that having an infectious disease caused fear, anxiety, and sadness, they were anxious about harming and infecting others, the social isolation process caused introversion, mental distress, and that they were worried about the possibility of being excluded and stigmatized by their social environment after discharge. Some of the participants 


\begin{tabular}{|c|c|c|}
\hline Descriptive characteristics & $\mathbf{n}$ & $\%$ \\
\hline \multicolumn{3}{|l|}{ Gender } \\
\hline Male & 4 & 50.0 \\
\hline Female & 4 & 50.0 \\
\hline \multicolumn{3}{|l|}{ Marital status } \\
\hline Married & 5 & 62.5 \\
\hline Single & 3 & 37.5 \\
\hline \multicolumn{3}{|l|}{ Place of residence } \\
\hline Metropolis & । & 12.5 \\
\hline City & 6 & 75.30 \\
\hline Countryside & । & 12.5 \\
\hline \multicolumn{3}{|l|}{ Education level } \\
\hline Primary+secondary school & 2 & 25.0 \\
\hline High school & 6 & 75.0 \\
\hline \multicolumn{3}{|l|}{ Employment status } \\
\hline Employed & 4 & 50.0 \\
\hline Unemployed & 4 & 50.0 \\
\hline \multicolumn{3}{|l|}{ Perception of income level } \\
\hline Low & 2 & 25.0 \\
\hline Moderate & 4 & 50.0 \\
\hline High & 2 & 25.0 \\
\hline \multicolumn{3}{|l|}{ Having children } \\
\hline Yes & 5 & 62.5 \\
\hline No & 3 & 37.5 \\
\hline \multicolumn{3}{|l|}{ Having a chronic disease } \\
\hline Yes & 2 & 25.0 \\
\hline No & 6 & 75.0 \\
\hline \multicolumn{3}{|l|}{$\begin{array}{l}\text { Having a family member } \\
\text { diagnosed with COVID-19 }\end{array}$} \\
\hline Yes & 5 & 62.5 \\
\hline No & 3 & 37.5 \\
\hline \multicolumn{3}{|l|}{ Symptoms of COVID-19* } \\
\hline Weakness, fatigue & 7 & 87.5 \\
\hline Dry cough & 5 & 62.5 \\
\hline Fever & 5 & 62.5 \\
\hline Muscle, joint pain & 2 & 25.0 \\
\hline Inability to taste and smell & । & 12.5 \\
\hline Shortness of breath & 2 & 25.0 \\
\hline Headache & 4 & 50.0 \\
\hline No symptom & । & 12.5 \\
\hline \multicolumn{3}{|c|}{ Being connected to a ventilator } \\
\hline Yes & 4 & 50.0 \\
\hline No & 4 & 50.0 \\
\hline \multicolumn{3}{|l|}{$\begin{array}{l}\text { Being volunteer for } \\
\text { plasmapheresis treatment }\end{array}$} \\
\hline Yes & 8 & 100 \\
\hline Age (year) $($ mean $\pm S D)$ & \multicolumn{2}{|c|}{$38.86 \pm 7.66$} \\
\hline
\end{tabular}

expressed their feelings when they were first diagnosed with COVID-19 as follows:

My dreams shattered. My blood pressure dropped a little. I was afraid a bit because of my heart disease. A disease coming from God, of course, but you are still scared. I wonder if I will die (7th participant).

I thought I would be one of those who survived this disease. I was scared, I was panicked a lot. I thought about how to overcome this situation. I believed that gradually but eventually, I would succeed (the patient moved from a lying position to a sitting position and replied the question) (4th participant).

Being infected with corona, of course... when I am talking on the phone, people are talking to me as if I were an AIDS patient. When we go out, because we are corona patients, now I am worried about how people will treat us in our social environment. I have such thoughts. I wonder how people will look at me. In other words, I know that being a corona patient is right now in our society...I don't know, people are a little prejudiced, so they can abstain from you. I haven't been out yet. I don't know what it will be like. (Ist participant)

A terrible feeling. I am glad that I am fine now, but when I get out of here and go home, I am afraid of infecting it. I haven't asked the doctors a lot about this topic. They haven't said. I'm afraid I will transmit it. I hope we will all get rid of it. (6th participant)

If necessary, we have to lock ourselves in a room and protect. When we go somewhere, we need to isolate ourselves. Of course, there is a fear of infecting others. I don't want to cause this situation (replied the question by fixing the mask). (7th participant)

I believe that I will recover, but I am worried about transmitting it to my family. (8th participant)

\section{Theme 2: Coping Styles}

The participants stated that after being diagnosed with COVID-19, they spent time in isolation by doing hobby-activity, talking with their beloved ones on the phone, watching television, and praying. The participants expressed their expectations for discharge, recovery, and life goals as meeting their beloved ones and fulfilling their longing for them, spending time at home, and they had values and beliefs such as gratitude and acting modestly.

I am praying a lot...for all patients, doctors, healthcare professionals... They have been really good, nice, and sensitive. I spend time doing something on the smartphone. There's not much to do in the room. I communicate with my beloved ones (through telephone). But I feel bored. (3rd participant).

I'm doing embroidery now. I'm looking out of the window. I am reading the Quran. I usually spend time in this room. There is not much opportunity. I sometimes watch TV and go for a walk. I am talking to my relatives on the phone. (5th participant)

First I will go to my home and isolate myself for 14-15 days. I will go to my village. I'll look out of the window onto my garden. Maybe I won't go out for a month. I just want to get out alive (smiling). (2nd participant)

\section{Theme 3: Provision of Health Services}

The patients in the study stated that they were satisfied with the attitudes and behaviors of physicians and nurses during the treatment. 
TABLE 2. Themes, Subthemes, and Codes in Interviews with Participants

\begin{tabular}{lcc} 
Themes & \multicolumn{1}{c}{ Subthemes } & Codes \\
$\begin{array}{l}\text { Theme l: emotional } \\
\text { reflections about the disease }\end{array}$ & Negative emotional responses & Fear \\
Panic & Anxiety \\
Anger & Hope \\
Adaptation & Faith \\
Sadness & Despair \\
Theme 2: coping styles & Having an infectious disease & Social isolation \\
Introversion & Concern
\end{tabular}

If it weren't for them, our situation would be terrible. May God be with our nurses. (7th participant)

Very much. Believe me, I am very pleased. Believe me, if I were in the service, I would not be able to stay there. There's no one there. There is always someone here. Even seeing other patients makes me happy. Here, there are passersby. There are nurses. I mean the name of intensive care is bad, but actually, that is not the case here. (3rd participant)

May Allah bless everyone. Our doctors, nurses never leave us alone. They always care for us. They give us food and clean our beds. I am very satisfied with the nurses. May Allah be pleased with all of them. May Allah bless our country. (6th participant)

\section{DISCUSSION}

The study was carried out with volunteer COVID-19 patients receiving treatment in the service after intensive care to investigate their perceptions of the disease and the treatment experiences.

\section{Emotional Reflections about the Disease}

Most of the patients expressed that they had negative emotional responses such as fear, panic, anxiety, and anger owing to the diagnosis of COVID-19. It is known that there is a relationship between the way the disease is represented in the mind of individuals and their reactions to the disease. ${ }^{25}$ Relevant literature shows that the anxiety of the public and healthcare workers increased during epidemic diseases. ${ }^{26-28}$ A study conducted in Hong Kong during the SARS outbreak in some countries in 2003 emphasized that psychological reactions such as high levels of stress, helplessness, and post-traumatic symptoms were common in the subjects. ${ }^{29}$ Another study in China reports that the COVID-19 outbreak means a severe trauma for humans which has elevated their anxiety level. ${ }^{22}$ It is thought that COVID-19 disease has a risk of infection and a fatal effect, causing feelings such as fear, anxiety, and panic in patients. Considering that patients undergoing COVID-19 treatment may experience psychological difficulties, it is recommended that physicians and nurses be sensitive, provide psychological support, and seek psychiatric consultation when necessary.

Participants in the study indicated that having an infectious disease caused fear, anxiety, and sadness, they were anxious about harming and infecting others, the social isolation process caused introversion, mental distress, and they are worried that they would be excluded and stigmatized by the social environment after discharge. In the literature, it is seen that the anxiety levels of individuals differ from country to country during epidemics. Taylor et al. ${ }^{26}$ conducted a study to evaluate the psycho-social effects of the equine flu epidemics in Australia and reported that $34 \%$ of the participants had high-stress levels. In the study conducted by Wang et al., ${ }^{21}$ in the first phase of the COVID-19 pandemics in China, more than half of the respondents evaluated the levels of psychological impact and anxiety as moderate.

Being stigmatized is defined as "the patient's feeling that he/ she has been rejected, isolated by society, and feeling embarrassed and insecure due to his/her illness." In a study of 3,0ll people in Hong Kong, participants listed the most stigmatizing diseases as HIV / AIDS, tuberculosis, and SARS, respectively. ${ }^{29}$ Society tends to stigmatize individuals with diseases that have infectious characteristics. We believe that there is a need to increase social awareness about the harmful effects of stigmatizing COVID-19 patients' mental health; otherwise, stigma may reduce their general functionality as a serious risk factor.

\section{Coping Styles}

Participants were spending the isolation period after being diagnosed with COVID-19 by doing hobby-activity, talking with 
their beloved ones on the phone, watching television, and praying. Coping is a cognitive and behavioral strategy that the person poses consciously or unconsciously to deal with the difficulties, needs, demands, and changes stemming from the environment. Coping styles vary according to the individual's internal resources and responses, family support, and cultural structure. $^{30}$ The literature suggests that individuals with physical illnesses often benefit from the strategies such as seeking information and social support, learning new skills, actively participating in treatment, coping through confrontation, adopting a positive approach, avoiding, sharing anxiety and emotions about the disease, maintaining hope, and seeking for emotional support in line with their beliefs. ${ }^{30,31}$ It is thought that the presence of social support resources, leisure activities, and the opportunity to worship according to their beliefs help the participants in our study to struggle with the disease.

The participants hoped for discharge and recovery, made plans such as meeting their beloved ones, fulfilling their longing for them after being discharged, spending time at home, and had values and beliefs such as gratitude, praying, acting modestly.

Psychological adaptation is a process that has biological and psychological dimensions associated with gains, losses, and struggles in the life of the patient. In the literature, the presence of psychological factors including denying, protecting hope, sense of trust, difficulty, and control are reported as positive compliance behaviors. ${ }^{32}$ Our study is consistent with the literature in this regard.

\section{Provision of Health Services}

The patients in the study stated that they were satisfied with the treatment and care they received during the treatment and the attitude and behavior of the healthcare professionals. Health personnel's personality traits, kindness, interest, professional attitudes, ways of presenting their knowledge and skills, and especially patient-nurse relationships play a critical role in patient satisfaction. ${ }^{33,34}$ It is reported in the literature that the most significant factor affecting patient satisfaction is communication and providing the patient with sufficient information, ${ }^{35,36}$ because the ability of healthcare providers to communicate with patients has a pivotal role in making patients feel valued or worthless. Patient-centered and individvalized care makes the patient feel valued and creates a trust relationship between people. In addition, feeling valued as an individual is in a sense related to being adequately informed. In many cases, healthcare professionals who determine the needs of individuals and provide information about these needs make patients feel valued. Various studies noted that the trust and satisfaction level of patients who are adequately informed about their condition and procedures with the healthcare personnel increased. ${ }^{33,35}$ Due to the nature of COVID-19 disease, visitors are not accepted, and patients receive treatment and care in single and isolated rooms, so it is thought that positive communication and information provided by healthcare workers positively affects patient satisfaction.

Psychological and sociocultural factors, religious values, and health policies can be effective in patients' perception of disease and treatment. It is recommended that healthcare professionals be aware of the psychosocial problems faced by the COVID-19 patients receiving treatment in the hospital, provide appropriate environments where patients can express their feelings and thoughts, establish therapeutic communication with the patients, provide information about the disease and treatment process, and monitor them for post-traumatic stress disorder.

\section{Strengths and Limitations}

The scientific rigor of our study is that it is the first qualitative study in Turkey to examine the perception of the disease and treatment of individuals diagnosed with COVID-19. The study reflects patients' perceptions of disease and their experiences during the COVID-19 treatment. Patients' disease perceptions may change after discharge. We aim to carry out a longitudinal follow-up study to determine the changes in perceptions of the disease over time. The limitation of the study is that although the researcher who interviewed the patients was not involved in the treatment and care of the patients, the patients did not report any negative feelings and experiences regarding their treatment. They may not have mentioned their negative experiences, because they thought that their treatment process would be negatively affected.

Acknowledgments: We would like to thank all the patients who gave their time and offered us their valuable insights.

Ethics Committee Approval: Ethical committee approval was received from the local Ethics Committee (No: 40465587-050.01.04-127), and permission was granted by the Council for Scientific Research Studies of the Directorate General of Health Services affiliated to the Ministry of Health, Republic of Turkey (No: 2020-05-02TI4-15-59).

Informed Consent: Written informed consent was obtained from all participants who participated in this study.

Peer-review: Externally peer-reviewed.

Author Contributions: Concept - C.U.S., M.A., A.U., M.S.; Design - C.U.S., M.A., A.U., M.S.; Data Collection - A.U.; Analysis and/or Interpretation C.U.S., M.A., A.U.; Writing - C.U.S., M.A., A.U., M.S.; Critical Review C.U.S., M.A.

Conflict of Interest: The authors have no conflicts of interest to declare.

Financial Disclosure: The authors declared that this study has received no financial support.

Disclaimer: The content is solely the responsibility of the authors.

Data Availability: The datasets generated during and/or analyzed during the current study are available from the corresponding author on reasonable request.

\section{REFERENCES}

I. Fung TS, Liu DX. Human coronavirus: Host-pathogen interaction. Ann Rev Microbiol. 2019;73:529-557. [CrossRef]

2. Bulut C, Kato Y. Epidemiology of COVID-19. Turkish J Med Sci. 2020;50:563-570. [CrossRef]

3. WHO. Coronavirus disease (COVID-19) situation dashboard. 2021. Available at https://who.maps.arcgis.com/apps/opsdashboard/ index.html\#/al9d5dlf86ee4d99b013eed5f637232d. Accessed February 24,2021 .

4. Turkish Republic Ministry of Health. Current situation in Turkey. 2020. Available at https: / / covidl9.saglik.gov.tr/. Accessed February $24,2021$.

5. Dikmen AU, Kına HM, Özkan S, İlhan MN. Epidemiology of COVID19: What we learn from pandemic. J Biotechnol Strategic Health Res. / 2020;I(special issue):29-36. 
6. Chen $Q$, Liang $M, L i Y$, et al. Mental health care for medical staff in China during the COVID-19 outbreak. Lancet Psychiatr. 2020;7(4):el5-el6. [CrossRef]

7. Yang $Y$, Li W, Zhang $Q$, Zhang L, Cheung T, Xiang YT. Mental health services for older adults in China during the COVID-19 outbreak. Lancet Psychiatr. 2020;20:30079.

8. Li SW, Wang Y, Yang YY, Lei XM, Yang YF. Analysis of influencing factors of anxiety and emotional disorders in children and adolescents during home isolation during the epidemic of novel coronavirus pneumonia. Chin J Child Health. 2020;287(I):I-9.

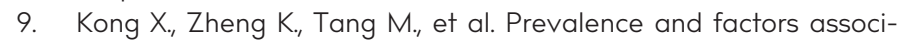
ated with depression and anxiety of hospitalized patients with COVID-19. medRxiv; 2020. [CrossRef]

10. Yang L., Wu D., Hou Y., et al. Analysis of psychological state and clinical psychological intervention model of patients with COVID19. medRxiv. 2020. [CrossRef]

II. Qi R., Chen W., Liu S., et al. Psychological morbidities and fatigue in patients with confirmed COVID-19 during disease outbreak: Prevalence and associated biopsychosocial risk factors. medRxiv. 2020.

12. Adhikari SP, Meng S, Wu YJ, et al. Epidemiology, causes, clinical manifestation and diagnosis, prevention and control of coronavirus disease (COVID-19) during the early outbreak period: A scoping review. Infect Dis Poverty. 2020;9(I):29. [CrossRef]

13. Cascella M, Rajnik M, Cuomo A, Dulebohn SC, Di Napoli R. Features, Evaluation and Treatment Coronavirus (COVID-19). Treasure Island, FL: StatPearls Publishing, 2020.

14. Cheng SK, Wong CW, Tsang J, Wong KC. Psychological distress and negative appraisals in survivors of severe acute respiratory syndrome (SARS). Psychol Med. 2004;34(7):I187-1195. [CrossRef]

15. Lee AM, Wong JG, McAlonan GM, et al. Stress and psychological distress among SARS survivors I year after the outbreak. Can J Psychiatry. 2007;52(4):233-240. [CrossRef]

16. O'Brien BC, Harris IB, Beckman TJ, Reed DA, Cook DA. Standards for reporting qualitative research: A synthesis of recommendations. Acad Med. 2014;89(9):1245-125I. [CrossRef]

17. Morrow R, Rodriguez A, King N. Colaizzi's descriptive phenomenological method. Psychologist. 2015;28(8):643-644.

18. Palinkas LA, Horwitz SM, Green CA, Wisdom JP, Duan N, Hoagwood K. Purposeful sampling for qualitative data collection and analysis in mixed method implementation research. Adm Policy Mental Health Mental Health Serv Res. 2015;42(5):533-544. [CrossRef]

19. Fusch PI, Ness LR. Are we there yet? data saturation in qualitative research. Qual Rep. 2015;20(2):1408-1416.

20. Lewis S. Qualitative inquiry and research design: Choosing among five approaches [Review of the book qualitative inquiry and research design: Choosing among five approaches (3rd ed.), by J. Creswell]. Health Promotion Practice. 2015;16(4):473-475. [CrossRef]

21. Wang C, Pan R, Wan X, et al. Immediate psychological responses and associated factors during the initial stage of the 2019 Coronavirus disease (COVID-19) epidemic among the general population in China. Int J Environ Res Public Health. 2020;17(5):1729. [CrossRef]

22. Zhang WR, Wang $K$, Yin $L$, et al. Mental health and psychosocial problems of medical health workers during the COVID-19 epidemic in China. Psychother Psychosomat. 2020;I-9. [CrossRef]

23. Vaismoradi M, Turunen $H$, Bondas $T$. Content analysis and thematic analysis: Implications for conducting a qualitative descriptive study. Nurs Health Sci. 2013;15(3):398-405. [CrossRef]

24. Marshall C, Rossman GB. Designing Qualitative Research. New Yok: Sage Publications, 2014:280-285.

25. Hekler EB, Lambert J, Leventhal E, Leventhal H, Jahn E, Contrada RJ. Commonsense illness beliefs, adherence behaviors, and hypertension control among African Americans. J Behav Med. 2008;31:391-400. [CrossRef]

26. Taylor MR, Kingsley EA, Garry JS, Raphael B. Factors influencing psychological distress during a disease epidemic: Data from Australia's first outbreak of equine influenza. BMC Public Health. 2008;

27. Goodwin R, Haque S, Neto F, Myers LB. Initial psychological responses to influenza $\mathrm{A}, \mathrm{HINI}$ ("Swine flu"). BMC Infectious Dis. 2009;16(4):9-166. [CrossRef]

28. Goodwin R, Gaines SO, Jr, Myers L, Neta F. Initial psychological responses to Swine Flu. Int J Behav Med. 20I0. [CrossRef]

29. Lau JTF, Yang X, Pang E, Tsui HY, Wong E, Wing YK. SARS-related perceptions in Hong Kong. Emerg Infect Dis. 2005;II:417-424.

30. Ozsoy I, Okyayuz UH. Coping skills of people with amputation: Case presentation. Klinik Psikiyatri. 2016;19:45-51.

31. Kocaman N. Factors that affected of psychosocial reactions of patients. J Atatürk Univ School Nurs. 2008;II(I):I0I-II2.

32. Ozdemir U, Tasci S. Psychosocial problems and care of chronic diseases. Erciyes Univ J Health Sci Fac. 2013;:l:I.

33. Coban IG, Kasikci M. Reliability and validity of the scale of patient perception of hospital experience with nursing care in a Turkish population. J Clin Nurs. 2010;19(13-14):1929-1934. [CrossRef]

34. Ozlu ZK, Uzun O. Evaluation of satisfaction with nursing care of patients hospitalized in surgical clinics of different hospitals. Int $J$ Caring Sci. 2015;8(I):19-24.

35. Karadağ $\mathrm{S}$, Taşçı $\mathrm{S}$. The factors affecting the nursing care given by the nurses working in Kayseri State hospital. J Health Sci. 2005;|4:|3-21.

36. Vural Ö, Vural G. Gynecological cancer patients satisfaction related to nursing care who take chemotherapy. Dokuz Eylul Univ Fac Nurs Electron J. 2013;6(I):17-25. 